\title{
Co-Catalyzed Radical Alkenylation of Alkyl Halides
}

Heck reaction

cobalt catalysis

radical addition

$$
\begin{aligned}
& \mathrm{R}^{1} \mathrm{X}+\mathrm{R}^{2}-\frac{\mathrm{Me}_{3} \mathrm{SiCH}_{2} \mathrm{MgCl}(1.5-3 \text { equiv) }}{\mathrm{CoCl}_{2}(5-10 \mathrm{~mol} \%), \mathrm{DPPH}(6-12 \mathrm{~mol} \%)} \\
& \mathrm{Rt}_{2} \mathrm{O} \text { or THF, r.t. to reflux } \\
& \mathrm{C}^{1} \text { - sec-, tert-Alk } \mathrm{R}^{2}=\mathrm{Ar}, \mathrm{Alk}, \mathrm{R}^{1}-\mathrm{R}^{2} \text { connected, etc. }
\end{aligned}
$$<smiles>C=Cc1cccc(C(=O)OCCCC)c1</smiles><smiles>[C+]C=[18O]</smiles>

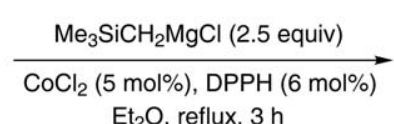
$\mathrm{Et}_{2} \mathrm{O}$, reflux, $3 \mathrm{~h}$

1.5 equiv<smiles>C=CCN(C)CCI</smiles>

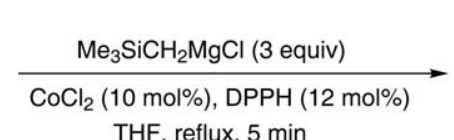<smiles>C=C1CCN([125I])C1</smiles>
$91 \%$ THF, reflux, 5 min
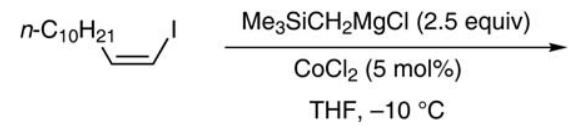

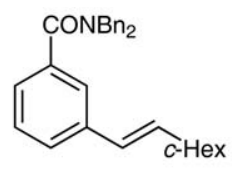

\section{$\mathrm{DPPH}=$
$1,6-$ bis(diphenylphosphino)hexane}

$95 \%$

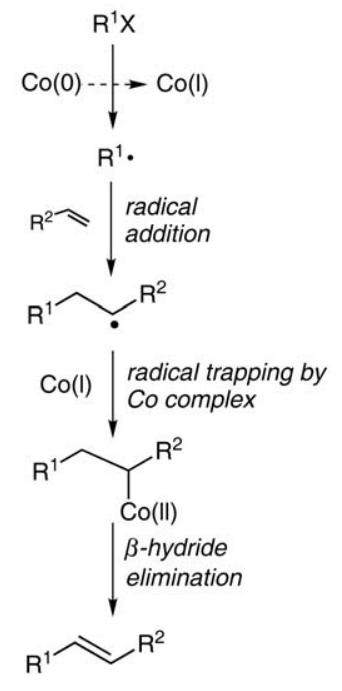

Significance: This work describes a novel method of intermolecular coupling of alkenes with alkyl halides in the presence of trimethylsilylmethylmagnesium chloride and a cobalt catalyst $\mathrm{CoCl}_{2}-1,6$ bis(diphenylphosphino)hexane. In many cases it is an alternative to the Heck reaction because it does not require expensive palladium catalysts. This method shows good functional-group compatibility. The reaction proceeds via a radical pathway. An intramolecular version of this process allows to create complex carbon frameworks. Additionally, a Co-catalyzed cross-coupling of iodoalkenes with $\mathrm{Me}_{3} \mathrm{SiCH}_{2} \mathrm{MgCl}$ leading to allyltrimethylsilanes is described.
Comment: This original method is especially convenient for the synthesis of polysubstituted styrenes, including those bearing functional groups. Mechanistically, the key steps of the process are the formation of a radical from the alkyl halide, its addition to the double bond and the trapping of the product by the Co(l) complex. Since the process is of radical nature, either a styrene has to be used to ensure the selective radical attack, or the reaction has to be performed intramolecularly, affording cyclization products. Interestingly, trimethylsilylmethyl magnesium halide is a unique Grignard reagent, allowing to perform such transformations. The reaction has obviously a high synthetic potential. 